symptoms or requesting a screen were the only reasons a test was ordered.

Conclusion Consideration should be given to amending the current chlamydia screening recommendation to annual screening of any sexually active person under 29 years.

Conflict of interest None declared.

\section{S07.4 BETTER, SOONER, MORE CONVENIENT: INCREASING YOUTH FRIENDLINESS OF FAMILY PLANNING SERVICES IN NEW ZEALAND}

Rose Stewart*. Family Planning, Wellington, New Zealand

10.1136/sextrans-2015-052270.47

Family Planning New Zealand has been working towards making services more accessible using technology since 2010. Young people want to access services via the web. There is a limitation to what you can do via phone and internet but some simple services can make a big difference to remoter clients. It started with merging the national clinical databases from 35 to two. We asked young people how they would like services to be. Setting up a national call centre streamlined client contact with us. At the same time a nurse results line was implemented and run via the call centre. I will share Family Planning New Zealand's progress so far and provide some information about the types of services we are now offering and planning to offer

\section{SO7.5 SOCIOCULTURAL CONTEXT AND SEXUAL HEALTH INFORMATION AMONG ADOLESCENTS AND YOUNG ADULTS}

${ }^{1}$ JS Leichliter*, ${ }^{1} \mathrm{R}$ Cramer, ${ }^{2} \mathrm{~A}$ Bodas LaPollo, ${ }^{2} \mathrm{~S}$ Hexem, ${ }^{1} \mathrm{HW}$ Chesson, ${ }^{1} \mathrm{MM}$ McFarlane. ${ }^{1}$ Centers for Disease Control and Prevention, Atlanta; ${ }^{2}$ Public Health Management Corporation, Philadelphia, USA

\subsection{6/sextrans-2015-052270.48}

Introduction Youth STD/HIV information seeking and policy changes (e.g. same-sex marriage) may vary by sociocultural context. We used state-level same-sex marriage laws in the United States (US) as proxy measure for sociocultural context to examine sources of STD/HIV information among youth within different contexts.

Methods We used Westlaw to collect 2013 US state-level laws related to same-sex marriage as a proxy for state sociocultural context related to STD/HIV. Same-sex marriage laws were coded as 1$)$ prohibited -- explicitly bans same-sex marriage $(\mathrm{n}=34)$, 2 ) not addressed - does not mention sex $(n=11), 3)$ recognised - explicitly permitted $(n=6)$. Laws were merged with data from a 2013 US survey of $15-25$ year olds $(n=4017)$ to assess sources of STD/HIV information among youth living in different sociocultural contexts.

Results Information sources for whether to have sex differed by sociocultural context. Youth living where same-sex marriage was recognised were more likely to report the following sources: doctor $(54.9 \%, \mathrm{p}<0.0001)$, social media $(15.5 \%, \mathrm{p}<0.01)$, and television/radio $(25.0 \%, \mathrm{p}<0.01)$; those living where same-sex marriage is prohibited (26.4\%) or not addressed $(26.3 \%)$ had the highest reports of religious institutions as a source. Traditional information sources (parent, doctor, school, religious institutions) about sexual relationships also differed by context; however, technological sources did not differ (internet, online expert, social media or television/radio). Those living where same-sex marriage was prohibited had the highest reports of parents $(p<0.01)$, religious institutions $(p<0.05)$ and magazines $(\mathrm{p}<0.05)$ as STD/HIV information sources. Youth living where same-sex marriage was recognised had the highest reports of using social media for STD information $(p<0.05)$. Finally, for information on preventing STD/HIV during sex, respondents where same-sex marriage is not addressed were least likely to report social media as a source $(\mathrm{p}<0.05)$.

Conclusion Readily available policies may be a useful proxy measure of sociocultural context in the field of STD/HIV prevention.

\section{S08 - Changing the trajectory of three related epidemics - HIV, viral hepatitis and sexually transmitted infections - through new global health sector strategies}

\section{S08.1 WHO GLOBAL HIGHLIGHTS AND CHALLENGES IN RELATION TO HIV, HEPATITIS AND STIS}

Nathalie Broutet*. World Health Organization, Geneva, Switzerland

\subsection{6/sextrans-2015-052270.49}

This presentation will introduce: the rationale for strategic action; opportunities provided by the emerging Sustainable Development Goal framework; proposed goals and targets overview of modelling and target-setting meetings and other processes informing the proposed goals, targets and milestones for the three strategies; and the structure of the strategies.

\section{S08.3 ENSURING EQUITY, REALISING RIGHTS, AND PROMOTING EVIDENCE: HOW CAN THE NEW WHO STRATEGIES RESPECT PRINCIPLES OF EQUITY AND JUSTICE AND STILL BE EFFECTIVE?}

Sarah Hawkes*. University College London, London, UK

10.1136/sextrans-2015-052270.50

WHO and the UN system have agreed upon a goal of Universal Health Coverage (UHC) - which will be included in the September 2015 Sustainable Development Goals. However, while the principles of human rights (including the right to health), equity and justice underlie commitments to the SDGs, the reality of priority-setting within health care systems is likely to influence decisions around resource allocation even within UHC. This talk will examine how decisions around priority-setting for STI prevention and care can be taken - what will prevail: rights or costeffectiveness? Are the two principles compatible and how will national programmes and international agencies allocate resources? These issues will be explored in depth in relation both to WHO's new STI control strategy and its wider commitment to $\mathrm{UHC}$ and human rights. 